\section{INICIATIVAS ESCENOGRÁFICAS EN ROSARIO: LO COOL COMO TECNOLOGÍA DE GOBIERNO DE SUBJETIVIDADES URBANAS ${ }^{1}$}

\section{Resumen}

El artículo se propone analizar un conjunto de iniciativas urbanas público-privadas, implementadas en el período 2007-2015 en la ciudad de Rosario, Argentina, desde el enfoque de la gubernamentalidad. La hipótesis que guía este trabajo sostiene que, teniendo como foco el embellecimiento, el entretenimiento y la movilidad, las iniciativas apuntan a crear una escenografía que proyecta, en la vidriera nacional e internacional, al "centro de la ciudad" y a los sujetos que lo habitan, lo transitan y lo consumen como saludables, felices, emprendedores y cool. Las mismas operan movilizando emociones, instrumentalizando deseos y

\section{SCENOGRAPHIC INITIATIVES IN ROSARIO: COOL AS A TECHNOLOGY FOR GOVERNING URBAN SUBJECTIVITIES ${ }^{1}$}

\author{
Luciana Noelia Ginga² \& Florencia Brizuela ${ }^{3}$
}

\section{Abstract}

This paper aims to analyze a series of publicprivate urban initiatives implemented from 2007 to 2015 in Rosario, Argentina from a governmental perspective. It is argued that embellishment, entertaining and mobility projects are intended to show the "downtown area of the city" and those who inhabit, move and consume within this area as healthy, happy, enterprising and cool individuals, both at the national and international levels. These projects are based on emotions, controlling desires and choices made by people and building different 
elecciones de los sujetos y construyendo diversas prácticas de habitar lo urbano que, bajo el signo de lo cool, promueven el consumo de la ciudad que se ofrece.

\section{PALABRAS CLAVE: INICIATIVAS URBANAS, TECNOLOGÍA DE GOBIERNO, URBANISMO ESCENOGRÁFICO, COOL.}

\author{
Recibido: 11-02-2017.
}

Aceptado: 31-08-2017.

1 Proyecto de Investigación y Desarrollo 1POL269, “El gobierno de lo social en la ciudad de Rosario: el gobierno de la fuerza de trabajo, el gobierno de la pobreza y el gobierno de la (in)seguridad y sus efectos de subjetivación", 2016-2020 financiado por la Universidad Nacional de Rosario, Facultad de Ciencia Política y Relaciones Internacionales.

2 Argentina. Facultad de Ciencia Política y Relaciones Internacionales, Instituto de Investigaciones, Universidad Nacional de Rosario. Correo electrónico: lupiginga@hotmail.com.

3 Argentina. Facultad de Ciencia Política y Relaciones Internacionales, Instituto de Investigaciones, Universidad Nacional de Rosario. Correo electrónico: florencia.agustina.brizuela@ hotmail.com.

164 revista invi 32(91): 163-187, november 2017 "cool" urban habitation practices aimed to promote consumption.

\section{KEYWORDS: URBAN INITIATIVES, GOVERN- BASED TECHNOLOGY, SCENOGRAPHIC URBANISM, COOLNESS.}

Received: 11-02-2017.

Accepted: 31-08-2017.

1 IPOL 269 Research and Development Project entitled "Social Governance in Rosario: The Government of the Workforce, Poverty and (in)Security and their Effects on Subjectivity" 20162020. School of Political Sciences and International Relations at the National University of Rosario. Project funded by the National University of Rosario.

2 Argentina. School of Political Sciences and International Relations, Research Institute, National University of Rosario. Email: lupiginga@hotmail.com.

3 Argentina. School of Political Sciences and International Relations, Research Institute, National University of Rosario. Email: florencia.agustina.brizuela@hotmail.com. SUbJeCtivities/Luciana Noelia Ginga y Florencia Brizuela 


\section{A modo de introducción}

A fines de los años ochenta y principios de los noventa, la intensificación de la competencia interurbana provocó un profundo cambio en los gobiernos de las ciudades. Socoloff, al respecto, sostiene que:

Bajo la creencia difundida que las ciudades y las regiones 'compiten', los gobiernos locales se dieron a sí mismos la tarea de generar las condiciones para atraer inversiones [Arantes, Vainer y Maricato, 2000], asumiendo explícitamente políticas llamadas de marketing urbano, que no se proponen otra cosa que 'vender' la ciudad (como marca, como objeto, como imagen, etc.) a inversores y turistas (Socoloff, 2013, p. 67).

La propuesta de marketing urbano promocionada implicó la puesta en marcha de un conjunto de actuaciones articuladas con el sector privado, asumiendo este último un rol fundamental en la planificación de las ciudades.

Rosario ${ }^{4}$ no escapó a dicho proceso. Desde fines de la década de 1990, el gobierno municipal ha

4 Rosario es una ciudad situada en el sureste de la provincia de Santa Fe, República Argentina. Es la ciudad más poblada de la provincia de Santa Fe y la tercera más poblada del país. En el año 2010 se proyectó una población estimada de alrededor de 948.312 habitantes, según datos proporcionados por el Instituto Nacional de Estadística y Censos.

\section{FIGURA 1. PUBLICIDAD DEL EVENTO “COOLTURA. FERIA DE DISEÑO"5.}

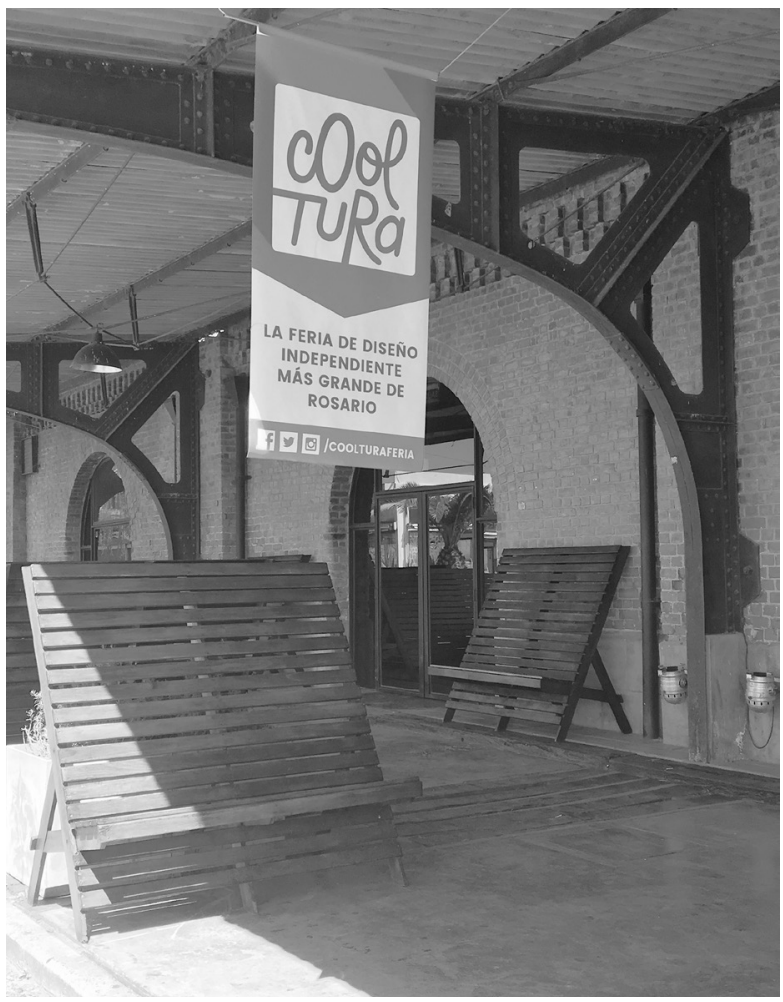

Fuente: Autores.

5 Foto tomada en ocasión de la realización de la feria independiente de productos de diseño, impulsada por un conjunto de emprendedores y diseñadores locales. Dicha feria se desarrolla los días domingo en uno de los galpones del antiguo ferrocarril, emplazado en la zona costera céntrica de la ciudad que, en los últimos años, ha sido revitalizada y convertida en una de las zonas más costosas de Rosario. 
planificado e implementado una serie de iniciativas público-privadas destinadas a consolidar la ciudad como una urbe creativa, ávida de recibir inversiones de capitales empresariales nacionales y/o extranjeros, sustentada en el fortalecimiento de la cultura y la innovación, como un territorio seguro (Sánchez y Ginga, 2014), con protagonismo y conectividad nacional y global, tal como versa en el Plan Estratégico Rosario 2010-2018. A partir de una contundente decisión política, Rosario debía y debe constituirse en una urbe emprendedora y empresaria, facilitando y acompañando este rumbo desde los diversos sectores gubernamentales y no gubernamentales.

Actualmente, el objetivo de constituir a Rosario como una ciudad emprendedora se expresa en un conjunto de iniciativas urbanas impulsadas tanto desde el gobierno local como desde organizaciones privadas. Estas iniciativas son: Street Food Rosario - Feria gastronómica callejera, Festival de Food Trucks de Rosario, el Paseo de los Olímpicos, la Calle Recreativa y el programa "Mi bici-tu bici".

El presente trabajo se propone problematizar, de modo exploratorio, estas iniciativas implementadas durante los dos últimos períodos de gestión

6 Estas iniciativas no son las únicas que reúnen las características mencionadas, pero su candente actualidad e imponente presencia las tornan significativas como analizadoras de la problemática objeto de este trabajo. municipal (2007-2011 y 2011-20157) desde el enfoque de la gubernamentalidad. Se pretende indagar qué racionalidades y tecnologías de gobierno urbanas despliegan. La hipótesis que guía la investigación sostiene que, teniendo como foco el embellecimiento, el entretenimiento y la movilidad, las iniciativas apuntan a crear una escenografía que proyecta, en la vidriera nacional e internacional, al "centro de la ciudad" y a los sujetos que lo habitan, lo transitan y lo consumen como saludables, felices, emprendedores y cool. Las mismas operan movilizando emociones, instrumentalizando deseos y elecciones de los sujetos y construyendo diversas prácticas de habitar lo urbano que, bajo el signo de lo cool, promueven el consumo de la ciudad que se ofrece.

Para la indagación, el trabajo retoma los desarrollos teóricos sobre gobierno y gubernamentalidad que inició Michel Foucault (2007, 2006 y 2001) a fines de la década de 1970 y que investigadores del mundo anglosajón analizaron durante los años noventa (Barry, Osborne y Rose, 1996; Rose y Miller, 1992; Burchell, Gordon y Miller, 1991). La perspectiva del gobierno en Foucault refiere a modos de acción y reflexión -estatales y no estatales- dirigidos a esbozar, guiar, administrar o regular las conductas

7 Durante el período 2007-2011 asumió la Intendencia de Rosario Miguel Lifschitz, mientras el período siguiente, 2011-2015, estuvo a cargo de Mónica Fein. Ambos pertenecen al Partido Socialista. 
de las personas. En el estudio de estos modos de acción resulta útil el análisis de dos dimensiones: la dimensión de las racionalidades políticas, entendidas como los campos discursivos donde el poder conceptualiza su ejercicio, y la dimensión de las tecnologías de gobierno (Rose y Miller, 1992), entendidas como un complejo de diversas fuerzas legales, arquitectónicas, administrativas, judiciales, entre otras, que buscan normalizar, ordenar y motorizar las aspiraciones de los sujetos.

En nuestra América ${ }^{8}$ y específicamente en Argentina, diversos/as autores/as se han interesado en esta perspectiva para dar cuenta y problematizar hechos propios de nuestras realidades (Murillo, 2008; Giavedoni, 2012; Campana, 2012; Mussetta, 2009; Marinis, 1999; Grinberg, 2007). Las iniciativas que se analizan en este artículo serán estudiadas en esos sentidos, es decir como un conjunto de mecanismos discursivos y prácticos que desplegados en lo urbano se dirigen a manejar las conductas y deseos de los sujetos.

El escrito se organiza en tres apartados. En el primero se retoman las investigaciones que analizan la constitución de las ciudades como ciudades-empresas (Sacchi, 2010; Harvey, 2007; Arantes, et al., 2000; Cuenya, 2000) y el modo en que el gobierno local rosarino fue moldeando sus intervenciones gubernamentales bajo la racionalidad urbana empresarial. En el segundo apartado se presentan las iniciativas urbanas, objeto de este estudio, destacando las condiciones de posibilidad de su emergencia, sus dinámicas de funcionamiento y sus emplazamientos. En el tercer apartado, para analizar las iniciativas, se recuperan los desarrollos de Naomi Klein acerca de lo cool (Klein, 2012), como técnica de gobierno empresarial que se traslada a la gestión y al gobierno de las ciudades y de las subjetividades. También en este tercer apartado se incorpora la clave de análisis que ofrece el urbanismo escenográfico (Girola, Yacovino y Laborde, 2011; Améndola, 2000), para, finalmente, apuntar algunas reflexiones más generales sobre el modo en que la articulación entre sectores públicos y privados diagraman e impulsan una configuración de lo urbano, escenográficamente cool, que interpela y apunta a constituir subjetividades deseantes.

\section{Metodología}

En función de concretar los objetivos de análisis, el trabajo asume un enfoque metodológico cualitativo con un diseño flexible (Mendizábal, 2000,

8 Este concepto refiere a la obra homónima de José Martí publicada en 1983, donde el autor desarrolla la idea de una América mestiza unificada en términos de soberanía frente a las amenazas coloniales. 
p. 67-70) que combina obtención, procesamiento y análisis de información. Para describir cómo se establecieron las articulaciones entre las diversas iniciativas urbanas, por un lado se apela a la reconstrucción historiográfica en clave de historia del presente, con el fin de reconocer sus condiciones de emergencia y analizar las modalidades de intervención urbanas que desplegó el gobierno municipal en los últimos años. Para ello, en el relevamiento se utilizan diversas fuentes secundarias, se recurre al análisis documental y se revisa la bibliografía existente sobre el tema.

Por otro lado, la lectura en términos de gobierno y gubernamentalidad orienta el análisis hacia el modo en que se racionaliza el ejercicio del poder a través de las iniciativas objeto de este estudio. Vale decir, estudiar cómo se pensaron, cómo se formularon, sobre qué actuaron, atendiendo a qué prácticas se generaron y a sus posibles efectos de subjetivación. Para esto es necesario apelar a la técnica de análisis documental. A través de ella se apunta a relevar las estrategias discursivas que atraviesan las iniciativas. En el enfoque propuesto, los discursos no solo producen efectos en las percepciones de lo social sino además en sus prácticas. Conforman realidad al interpelar a los sujetos en su cotidianeidad aun sin que éstos tengan, necesariamente, conciencia de ello (Murillo, 2008).

Por lo dicho y entendiendo el poder como relación social, el trabajo se concentra en los engranajes y las prácticas -sean discursivas (documentos) o extradiscursivas (instituciones) - a partir de las cuales el mismo funciona y circula. Las preguntas se dirigen a mostrar cómo -más que por qué- tal régimen de prácticas se ha desarrollado en una dirección y no en cualquier otra. Preguntarse por "el cómo significa no buscar las intenciones ocultas o la esencia última de un fenómeno, sino estudiar los mecanismos concretos por medio de los cuales el poder efectivamente se ejerce" (Campana, 2012, p. 24).

En consecuencia, para estudiar cómo funcionan las iniciativas se retoman los documentos oficiales emitidos por el gobierno local en su página web, al tiempo que se tiene en cuenta la folletería publicitada por las entidades privadas. Los documentos que se analizarán son trabajados como monumentos, es decir, se:

alude al hecho de que todo monumento (estatua, placa recordatoria) fue producido con una cierta intencionalidad en una relación de fuerzas determinada, con un cierto propósito de producir un modo de rememorar el pasado o de percibir el presente. Leer al documento como monumento, entonces, supone asumir que él no puede reflejar o rememorar la realidad tal cual fue, sino solo puede ser analizado según el modo en que ha circulado, cómo ha sido utilizado, por quiénes, en qué circunstancias. Significa comprender que él también es 
leído desde una cierta perspectiva y que por ende no refleja lo real del pasado tal como ocurrió. El documento entendido como monumento nos adentra en la 'historia efectiva', en la cual no hay unidades fijas, sino proliferación constante (Murillo, 2012, p. 26).

Así, la historia no supone ser la memoria de lo que pasó, sino la reconstrucción de sus efectos múltiples en los cuerpos y en los modos de relacionamiento.

Asimismo, para comprender la retórica en la que se asienta la implementación de estas iniciativas se toman dos fuentes: las publicaciones de la prensa y los discursos públicos pronunciados tanto por funcionarios políticos responsables de la implementación de dichas iniciativas, como por las organizaciones empresariales involucradas en las mismas. Para llevar a cabo esta tarea de recolección y recorte de información se realiza un relevamiento on line de noticias relacionadas con las iniciativas en los diarios de mayor circulación local: el Diario La Capital, la Revista ON24, Rosario 3; así como también en notas de páginas web de medios alternativos locales -vinculados a empresas, gremios, etc.-, entre ellos: Conclusión - Diario Digital Rosario, Impulso negocios y Diario Porven.
Dichas fuentes secundarias son leídas y analizadas a partir de la realización de una matriz de principales indicadores vinculados a nuestro objetivo, entre los que se cuentan las menciones a: los propósitos de las iniciativas, sus modos de funcionamiento, las propuestas de ejecución, la caracterización de la población a las que se dirigen, su ubicación geográfica, entre otros. Con esta caracterización se pretenden conocer las emociones, deseos, aspiraciones y elecciones que las iniciativas buscan inducir en los sujetos.

Cabe aclarar que el sujeto, en el enfoque de la gubernamentalidad, no es idéntico al autor de un discurso o al punto de partida de un conjunto de prácticas, sino a un lugar vacío que puede ser ocupado por individuos diferentes. No hay sujeto trascendental que haría posible una serie de enunciados/prácticas, sino que para cada una de ellas existen emplazamientos de sujetos variables. De modo que no se trata de analizar las emociones, los deseos y las aspiraciones a través de la información que los actores brinden vía la realización de entrevistas o encuestas. Se trata más bien de indagar qué emociones, deseos y aspiraciones producen las iniciativas aquí estudiadas, con sus discursos y prácticas, y qué efectos de subjetivación se derivan de ellas. 


\section{Las ciudades como empresas: el "nuevo" rol de los gobiernos locales}

En el año 2010, en el marco de la intendencia de Miguel Lifschitz (actualmente gobernador de la provincia de Santa Fe), se realizó una convocatoria dirigida a empresarios y emprendedores de la ciudad de Rosario para el encuentro denominado "Rosario: empresa de todos". Allí el entonces intendente pronunció las siguientes palabras: "La idea era reconocer y agradecerles a todos los empresarios y emprendedores de Rosario que están comprometidos con la ciudad, que colaboran y participan cotidianamente en diversos proyectos e iniciativas porque son amigos de esta gran empresa que es la ciudad de Rosario" ("Los reconocimientos de Rosario", 2010). Las palabras de la máxima autoridad política de la ciudad se inscriben en un proceso que le antecede y que ha continuado hasta nuestros días.

Se trata del despliegue de una racionalidad política empresaria de gestión, que se expresa en la dinamización de un sistema de pensamiento sobre la naturaleza de una práctica de gobierno urbano capaz de hacer a esa actividad pensable y practicable, tanto para gobernantes como para gobernados. Laval y Dardot enuncian:
La racionalidad empresarial presenta la ventaja incomparable de articular todas las relaciones de poder en la trama de un mismo discurso. El léxico de la empresa encierra, a este respecto, un potencial de unificación de los diferentes "regímenes de existencia", lo cual explica que los gobiernos recurran mucho a él. En particular, permite articular los objetivos de la política en curso con todas las componentes de la vida social e individual (2013, p. 336).

La racionalidad política empresaria, sostiene Brizuela (2015), emerge a lo largo de los años '80 en un contexto atravesado por las llamadas políticas de ajuste estructural en nuestra América. Las ciudades comienzan a ser programadas como empresas, como agentes económicos que actúan en el contexto de un mercado y encuentran en éste la regla o el modelo de planeamiento y ejecución de sus acciones. Según Harvey (2007), el "nuevo paradigma empresarial" plantea que para las ciudades es provechoso adoptar una actitud empresarial respecto al desarrollo económico. Mientras que para Theodore, Peck y Brenner (2009), las iniciativas que promueve el enfoque empresarial urbano (el marketing territorial, el impulso a las asociaciones público-privadas y las nuevas formas de promoción local) se erigen como un conjunto de políticas neoliberales cuya última meta es movilizar espacios de la ciudad tanto para el crecimiento 
económico orientado al mercado, como para las prácticas de consumo de las élites.

En la literatura analizada, tres principios definen conceptualmente al empresarialismo urbano. El primero de ellos es la alianza entre el sector público y el sector privado, pensada como un instrumento que sirve para atraer fuentes de financiación externas, nuevas inversiones directas o nuevas fuentes de empleo. El segundo principio es la orientación empresarial de las actividades que emprenden las alianzas del sector público y del sector privado, de orientación y diseño especulativos. Por último, el tercer principio es la construcción o mejora de lugares, es decir, el impulso a los llamados "proyectos urbanos" en contraposición a la planificación que piensa el territorio en su totalidad, en función de proyectos económicos de mayor alcance (como vivienda, educación, etc.) orientados a mejorar las condiciones y la calidad de vida y trabajo dentro de una determinada jurisdicción.

Estos principios, como premisas prácticas de actuación, demandan que los Estados locales desplieguen un rol proactivo, como promotor de la actividad privada, diferente al rol pasivo de antaño asociado a la regulación del uso del suelo y a la provisión de servicios básicos: barrido, limpieza, alumbrado (Brizuela, 2015). En adelante, los municipios son exhortados a adoptar nuevas responsabilidades y a un mayor activismo económico que incluye diversas acciones: promover la ciudad al exterior; producir innovaciones político-administrativas para generar mecanismos de cooperación social y participación ciudadana; construir alianzas con el sector privado que proporcionen el marco institucional para que las ciudades compitan en el mercado global, combinando recursos privados con capacidades gubernamentales locales, y facilitar la construcción de nuevos mercados (Cuenya, 2000; "Ciudades competitivas", 2007).

De este modo, la planificación de políticas urbanas, bajo el enfoque empresarial, muestra características que en otros tiempos distinguieron a las empresas privadas, como la inventiva, la asunción de riesgos, el afán promocional o el lucro. Estas características coinciden con el objetivo más global que estructura el nuevo rol de los gobiernos locales: hacer un uso pleno de los mecanismos del mercado para alcanzar metas públicas. Este objetivo no es azaroso en el caso de las ciudades argentinas, sino que es coincidente con un marco más general en el cual el influjo de las privatizaciones, la descentralización y la rápida desestructuración del modelo productivo anterior causan dificultades de orden económico y crecientes demandas sociales que los municipios deben resolver sin suficientes recursos para ello (García Delgado, 1998). Rosario atraviesa este conjunto de transformaciones desarrollando también una larga tradición en la implementación de políticas que se configuran bajo esta matriz empresarial, como se verá a continuación. 


\section{La configuración empresarial del gobierno urbano rosarino}

Los principios y las políticas que promueve el enfoque de la gobernanza urbana empresarial desembarcaron en Rosario durante la década de 1990 (Sacchi, 2010; Brizuela, 2015). A mediados de dicha década, en el contexto de una grave crisis económica y en un clima de desconfianza hacia el sistema político representativo, la gestión local de Hermes Binner ${ }^{9}$ se propuso afianzar índices de competitividad y productividad del sistema económico territorial de acuerdo a las exigencias del nuevo momento histórico.

Con ese objetivo, las gestiones socialistas comenzaron a emplear diversos métodos de concertación público-privada a través del diseño e implementación de iniciativas de desarrollo local y de planificación estratégica. Entre estas iniciativas, el Plan Estratégico Rosario (1998) ocupó un lugar central, ya que habilitó un espacio en el cual el municipio definió junto a los principales intereses del sector privado el proyecto de ciudad que se buscaba gestar, suministrando, paralelamente, un marco de referencia para que las empresas pudieran orientar sus decisiones y decidir sus estrategias (Brizuela, 2015; Vera, Roldán y Pascual, 2016).

9 Intendente de Rosario desde el año 1995 a 2003 y gobernador de la Provincia de Santa Fe desde 2007 a 2011.
Rosario debía convertirse en centro geopolítico y económico de una amplia región metropolitana y central, en puerto y puerta del Mercosur. Hacia allí se encaminaron las obras de infraestructura creadas junto al gobierno nacional y provincial, instalando a Rosario como núcleo polimodal de transporte y servicios. Simultáneamente, el municipio, a lo largo de las gestiones socialistas, impulsó un conjunto de intervenciones urbanas que apuntalaron el perfil de servicios que adquirió la ciudad. Las intervenciones incluyeron: la optimización de las condiciones de acceso y atravesamiento de la ciudad mediante la mejora de calles; aperturas de nuevos trazados y refuncionalización de arterias ${ }^{10}$; la urbanización del frente costero, su embellecimiento y puesta en valor a través de la instalación de nuevos usos terciarios; y la creación, rehabilitación y reconversión de distintos espacios en infraestructuras creativas y patrimonio urbano.

En todas estas actuaciones participó el capital privado a través de diversos mecanismos: concesiones de obra pública, convenios urbanísticos, convenios de esfuerzo compartido y préstamos contraídos con el Banco Interamericano de Desarrollo. El Estado local se configuró, de este modo, como facilitador de las acciones privadas y la concertación de estos dos sectores se convirtió en el mecanismo central de planificación del desarrollo urbano y

10 Sobre la relación circulación-ciudad véase Mongin, 2006, p. 127-156. 
económico de la ciudad. Sus vínculos dieron lugar a diferentes prácticas -formales e informales- que aumentaron el poder de incidencia del empresariado en el gobierno urbano de Rosario.

Del conjunto de intervenciones arriba comentadas, en los últimos años se ha destacado un objetivo particular en los esfuerzos y prácticas gubernamentales: mostrar a Rosario en una vidriera nacional y, fundamentalmente, internacional. Al respecto, valgan las palabras del actual gobernador Miguel Lifschitz:

Rosario es la ciudad en Argentina y una de las ciudades de América Latina con más reconocimientos internacionales; integra, en lugares relevantes, todas las redes y foros internacionales de ciudades. Es la ciudad que más construye y que ha producido la transformación urbana más sorprendente de la Argentina en la última década [2000-2010] y es también la capital cultural del país, un lugar legítimamente ganado; y es el destino turístico emergente más notable de la Argentina, y es la ciudad que invirtió más recursos propios en infraestructura, accesos viales y sistema de saneamiento ("Los reconocimientos de Rosario", 2010).
Ahora bien, aún sin contar con la capacidad administrativa y burocrática que cualquier capital provincial argentina posee, la proyección de Rosario a nivel global y nacional, en la actualidad, asume una característica específica: la elaboración de una imagen de ciudad que la asocia a una urbe cosmopolita, joven, cultural y turística. Estos atributos pueden ser localizados en las iniciativas que se presentan a continuación.

\section{Iniciativas urbanas}

A pesar de las diferencias que atraviesan a cada una de las siguientes iniciativas -algunas se realizan en determinados momentos del año, otras se mantienen regularmente y otras funcionan de forma cotidiana-, lo que las equipara es el modo en que han nacido, su forma de gestión públicoprivada, su intento de consolidarse como espacios creativos, cool, globales-globalizados ${ }^{11}$, y su anclaje en el centro de la ciudad.

En primer lugar se destaca el funcionamiento de Street Food - Feria gastronómica callejera.

11 Las iniciativas "globales y globalizadas" refieren a aquellas prácticas que están dirigidas a sujetos que se constituyen en "ciudadanos/as del mundo", en tanto pueden disfrutar y hacer uso de estos mismos servicios manteniendo sus hábitos de consumo, así se encuentren en París, Río de Janeiro, Ámsterdam, Nueva York o en Rosario. 
Lanzada por segunda vez en 2015, esta feria se lleva a cabo en el Boulevard Oroño, uno de los bulevares más emblemáticos de Rosario, donde los restaurantes del barrio Pichincha ${ }^{12}$ salen a la calle a ofrecer, a través de sus stands, menús de alta cocina, saludables y en algunos casos dietéticos y orgánicos. Los organizadores la presentan como una propuesta cultural y gourmet (Conta, 2015), un espacio y una atracción que la ciudad necesitaba, al tiempo que detectan una supuesta gran demanda de estos eventos. Bajo el lema "Gastronomía, arte y diseño" ("A la espera", 2016), la feria ofrece para degustar comidas variadas que van desde la tradicional hamburguesa hasta paellas y pescados a la parrilla, así como también clases magistrales a cargo de reconocidos chefs de la Fundación Rosario Cocina Ideas (RCI). En estas ocasiones, el barrio se constituye en el articulador de asociaciones de emprendedores que trabajan "a pulmón" para realizar la feria ("Street Food Rosario", 2015).

12 El barrio Pichincha es uno de los más antiguos y con más historia de la ciudad. Hoy se ha convertido en uno de los espacios de mayor rentabilidad económica para el negocio gastronómico.
En segundo lugar, otra de las iniciativas a remarcar es el Festival Food Trucks ${ }^{13}$ de Rosario, llevado a cabo por primera vez en abril de 2016. Con una apuesta similar a Street Food - Feria gastronómica callejera, en este caso el impulso estuvo a cargo de la Cámara de Food Trucks local y la organización fue dirigida por la Estación Fluvial ${ }^{14}$. La iniciativa, en principio netamente privada, contó con el apoyo público y la sanción de una ordenanza que la autorizó a funcionar. La ordenanza 9.444, aprobada en octubre de 2015, modificó la ordenanza 7.703, que regulaba el ejercicio del comercio en la vía pública y espacios verdes, incorporando la figura de los foodtrucks dentro de las formas de venta de comida habilitadas por la municipalidad.

La sanción de la norma en el concejo generó la oposición de dueños de bares y restaurantes, que consideraban este tipo de comercios como "una competencia desleal, debido a que no tiene los gastos impositivos y de mantenimiento que genera un local" ("Un festival como prueba", 2016).

13 Camión de comida en su traducción al español.

14 La estación Fluvial es un espacio frente al río que ofrece paseos de navegación por las islas y el Paraná, y además cuenta con bares, restaurantes y salones de eventos. Se constituye en un lugar privilegiado de la costa frente al río de gestión exclusivamente privada. Recuperado de http://www.lafluvialrosario. com.ar/. 


\section{FIGURA 2. STREET FOOD - FERIA GASTRONÓMICA CALLEJERA, CIUDAD DE ROSARIO.}

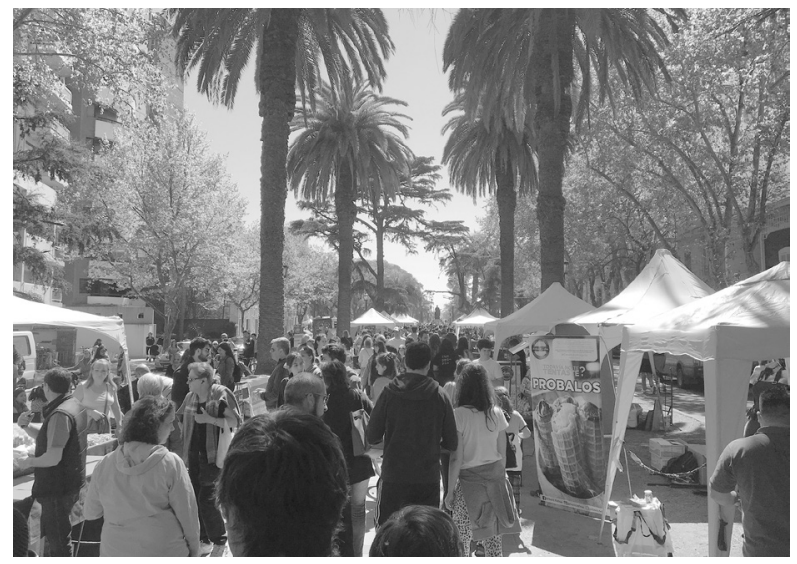

Fuente: Autores

La principal diferencia que presenta esta propuesta con la de un "carrito de comidas rápidas"15 es que los Food Trucks son atendidos por cocineros profesionales, de modo que la comida que se ofrece, si bien se trata de comidas rápidas, posee el calificativo de gourmet. Al tiempo que se apunta a otro público y a otros clientes que el que usualmente consume en los "carritos de comida rápida", la estética de estas experiencias, importadas de ciudades como Nueva York o Londres, la convierten en materia de visita de sectores medios y altos.

15 Los carritos de comida rápida en Argentina se emplazan en los parques de la ciudad y en las cercanías de las canchas de fútbol en ocasión de partidos, donde en general se ofrece, entre otros alimentos, el tradicional choripán.
Por otra parte, el Paseo de los Olímpicos constituye otra de las iniciativas relevadas. En el año 2015 fue construido como un espacio para el reconocimiento del vínculo social con los deportistas rosarinos en todas sus instancias, valorando especialmente a deportistas olímpicos y paralímpicos. La implementación de esta acción fue llevada adelante por la Municipalidad de Rosario junto al Centro Comercial "Paseo Pellegrini", uniendo 20 comercios gastronómicos tradicionales en la avenida con el objetivo de potenciar y mejorar esa zona tradicional e histórica ("Un paseo olímpico", 2015). El paseo consiste en diversas placas de granito colocadas a lo largo de ocho cuadras en ambas manos, donde se registra el nombre de los/as deportistas olímpicos y paraolímpicas locales que se hayan destacado. Las veredas amplias y de gran circulación la vuelven ideal para emplazar allí el homenaje.

Desde el año 2010, en el marco de la Red de Ciclovías Recreativas Unidas de las Américas -iniciativa que llevan adelante varias ciudades del continente americano, promoviendo un estilo de vida más saludable-, la Municipalidad de Rosario organiza la Calle Recreativa. Ésta consiste en destinar, los domingos a la mañana de 8 a 13 horas, los principales bulevares de la ciudad para que los ciudadanos puedan transitarlos caminando, en bicicleta, skate, rollers, etc. Es un circuito de 28 kilómetros que se supone libre de autos, motos y transporte público. 


\section{FIGURA 3. CALLE RECREATIVA, ROSARIO.}

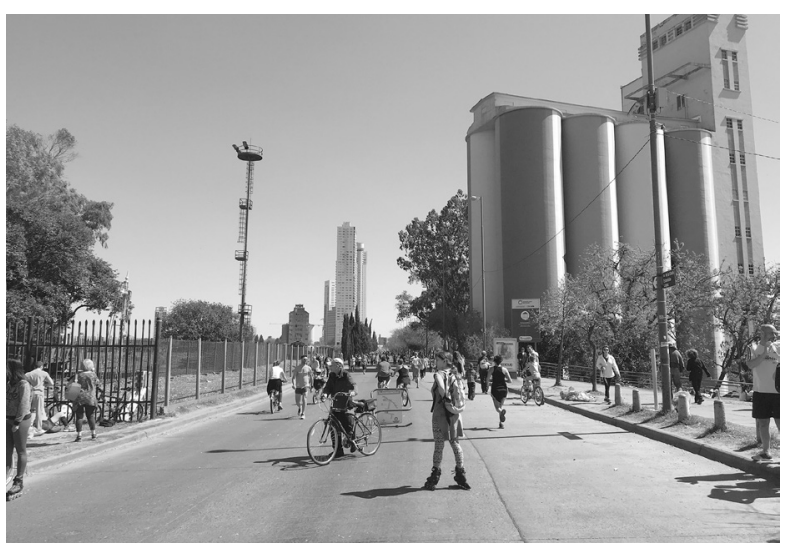

Fuente: Autores.

Así la retrataba años atrás el diario La Capital, uno de los principales de la ciudad:

Rosario es la primera ciudad del país en implementar un circuito recreativo permanente, libre de autos y motos. Y es por ello que cada domingo, un promedio de 30 mil usuarios, con algunas jornadas récord de más de 60 mil, disfrutan del circuito de 28 kilómetros convirtiendo a la Calle Recreativa en una alternativa masiva de convivencia, encuentro, esparcimiento, vida saludable y actividad física ("La Calle Recreativa", 2013).
Argumentos similares pueden leerse en la página web del gobierno municipal ${ }^{16}$, en la cual se describen los beneficios que conlleva la implementación de esta iniciativa: disminución de la contaminación ambiental y los niveles de ruido; reducción de la congestión vehicular; recuperación de las calles para el encuentro ciudadano, impulsando la convivencia con valores democráticos, respeto y tolerancia; promoción de hábitos de vida saludables, etc.

En relación con la Calle Recreativa, en el año 2015 tuvo lugar en la ciudad de Rosario el X Congreso de Ciclovías Recreativas de las Américas, organizado por la Red de Ciclovías, asociación internacional de entidades público-privadas que apoyan y difunden la creación y el funcionamiento de estas experiencias en ciudades de nuestro continente("X Congreso de la Red", s.f.).

Finalmente, el programa "Mi bici-Tu bici" constituye la última iniciativa a trabajar. Según versa en la página oficial de la Municipalidad de Rosario ${ }^{17}$, este programa, en funcionamiento desde el 1 de diciembre de 2015, creó el primer sistema automatizado de alquiler de bicicletas públicas de la ciudad de Rosario, que permite a los usuarios realizar recorridos variables a través de un nuevo sistema de transporte público. Las estaciones son puestos

16 Página web de la Municipalidad de Rosario: http://www.rosario. gov.ar/web/ciudad/deportes-y-recreacion/calle-recreativa.

17 Para ampliar, consultar la página web del programa: http:// www.mibicitubici.gob.ar/comoutilizar.aspx. 
fijos automatizados con un módulo y varios puntos de anclaje para bicicletas. Están distribuidas en lugares de intenso uso público y cercano a sedes universitarias.

El sistema abarca 18 estaciones localizadas en el área central y su entorno, y cuenta con más de 200 bicicletas en servicio más un stock para reposición durante tareas de mantenimiento, sumando en total 480 bicicletas. La municipalidad destaca entre sus fortalezas que el sistema funciona con paneles de energía solar, promoviendo el ahorro de recursos, la sustentabilidad y el cuidado del medio ambiente, siendo monitoreado durante las 24 horas por el Centro de Monitoreo de la Movilidad.

Como se mencionó al comienzo del apartado, todas las iniciativas abordadas se localizan en el Distrito Centro de la ciudad ${ }^{18}$ e intentan constituir espacios creativos, globales y saludables, teniendo la cooperación público-privada un rol fundamental en su despliegue. Para ello movilizan deseos asociados a una vida que supone el cuidado del cuerpo, a través de la actividad física o el consumo de comida saludable, así como también de opciones gastronómicas gourmet, sin perder al mismo tiempo el carácter cosmopolita que implica disfrutar de actividades que pueden encontrarse en las ciudades del mundo turísticamente más promocionadas. De

18 La ciudad de Rosario se encuentra descentralizada administrativamente en seis distritos: Centro, Norte, Noroeste, Oeste, Sudoeste y Sur. este modo, la apelación a lo cool a menudo adopta un papel primordial en el incentivo al consumo de estos espacios, interpelando y construyendo en el mismo proceso subjetividades que también son configuradas bajo dicha racionalidad. La actitud inducida se relaciona estrechamente al sujeto empresario/a de sí, ya que tendencialmente todo debe ser vivido mediante la grilla empresarial: el "trabajo, pero también el consumo, sin olvidar el ocio" (Laval y Dardot, 2013, p. 341). El sujeto debe, no solo, producir más sino gozar cada vez más. De esta interrelación permanente y perpetua, el/la empresario/a de sí, debe encontrar los modos de hacer emerger su propia transformación y adaptación, a través de la búsqueda de una verdad de sí que lo llevará a sentirse realizado y a la felicidad, reforzamiento central del management neoliberal (Nicoli y Paltrinieri, 2014).

\section{Rosario y las iniciativas políticas cool}

En "No Logo", Naomi Klein (2012) estudia el modo en que la cultura juvenil ha sido objeto de conversión en artículo de consumo. Sostiene que desde las crisis de las marcas en la década de los noventa, 
las empresas se vieron ante una clara necesidad de hallar una nueva clase predominante de clientes: los/as jóvenes. Si bien este ha sido un fenómeno que tiene su epicentro en países como Estados Unidos o Gran Bretaña, la difusión de sus lógicas adquiere escala planetaria.

Según Klein, la juventud se constituye en el principal cliente de las marcas, mientras que la cultura juvenil, concebida como lo novedoso, lo alternativo, lo cool, se conforma en clave vehiculizadora del aumento exponencial de las ventas. Las ciudades, en este contexto, también se reconfiguran como marcas y adoptan una actitud empresarial que busca posicionarlas en el mercado global para atraer capitales, turistas, créditos de organismos internacionales, exposiciones de arte, congresos, conferencias, etc. De modo que lo cool, instaurado como técnica en y desde las empresas durante los noventa, se traslada a las ciudades ${ }^{19}$ con el objetivo de hacer cool a un país o a una urbe. Al respecto, Klein avizora: "siendo la misión de nuestros ejecutivos insuflar profundamente en sus empresas este estilo cool, podemos anticipar que pronto el mandato de nuestros gobernantes electos será 'hacer cool el país"' (Klein, 2012, p. 118).

19 Así como el poder disciplinario (Foucault, 2006) emerge en las cárceles, en las escuelas, en los manicomios, el poder managerial emerge en las empresas y es adoptado por los gobiernos nacionales y locales como modo de despliegue de iniciativas gubernamentales que en las ciudades se refleja en la construcción de su estética, en las estrategias de su circulación, etc.
Las ciudades o los países se convierten en marcas, desarrollan una estética, imprimen un estilo y adoptan un color, el cual usualmente coincide y se vuelve indefectiblemente representativo del partido político de gobierno y en consecuencia de la ciudad. Las ciudades latinoamericanas no son ajenas a estos procesos. Según Delgadillo (2014), nuestra región históricamente ha estado vinculada e interesada en los avances urbanísticos, sociales y tecnológicos de Europa y Norteamérica. Se trata de una relación dialéctica y asimétrica, pero también de adaptación y transformación de ideas foráneas. Por lo tanto, no se trata de extrapolar conclusiones analíticas que han emergido en otras latitudes, sino de concentrarse en la particularidad de las condiciones de emergencia de fenómenos en nuestros contextos urbanos.

En este sentido, Murillo al hablar de la ciudad de Buenos Aires sostiene:

Hoy una ciudad puede perder sus claroscuros históricos para teñirse de un color determinado y ese color [puede] atrapar la vista y conducir las conductas de sujetos y poblaciones sin conciencia de ello (es el caso de una ciudad pintada de rosa y patrocinada por Barbie en 
Inglaterra), así el medio de transporte, las calles, los lugares públicos y privados ligados a la salud, al ocio o a la educación son esmaltados en un color determinado y con algunas frases superficiales que apelan a lo emocional en un sentido vago; color y frases que evitan la palabra que incita a la reflexión, y por el contrario condensan significados imaginarios, ligados a la completud, para quienes transitan esos lugares" (Murillo, 2016, p. 3).

En esta estrategia, el mercado juvenil "estimula" al gobierno local rosarino en sus acciones. La juventud comienza a jugar un papel fundamental como segmento poblacional al cual dirigirse en las iniciativas analizadas. Mientras el Paseo de los Olímpicos revaloriza a figuras como Lionel Messi y Luciana Aymar ("Paseo de los Olímpicos", s.f.), jóvenes deportistas exitosos en competencias internacionales, en los folletos y videos que promocionan el programa Mi bici-Tu bici aparecen en reiteradas ocasiones jóvenes con mochilas y cuadernos dispuestos al traslado hacia sus facultades. La recuperación de imágenes juveniles también está presente en la promoción de la Calle Recreativa, donde niñas y jóvenes recorren el circuito en rollers, skates y bicicletas.

Sin embargo, en Rosario no es a la juventud en general a la que apuntan las iniciativas público-privadas estudiadas, sino a un tipo específico de juventud que es, al mismo tiempo, constituida por ellas. Se trata de jóvenes de clases medias y/o altas que residen en barrios céntricos, generalmente universitarios/as o que se dedican a las artes o al trabajo en empresas y que aspiran a recorrer circuitos privilegiados de entretenimiento y distracción acordes a los que se ofrecen en las principales ciudades del mundo. La apelación a los deseos de experimentar nuevas sensaciones y ser parte de un circuito de entretenimiento y de hábitos de consumo, similares a los desarrollados en las principales capitales del mundo, genera el efecto de pertenencia a una élite privilegiada global, materializada en ciertas zonas urbanas céntricas y locales. Así, lo local se resignifica a través de los deseos y el goce, en un eslabón encadenado a tendencias cosmopolitas y elitistas.

Por otro lado, las iniciativas interpelan a los/las jóvenes activando un doble proceso de visualización de espacios y prácticas y de creación y facilitamiento de espacios públicos para nuevos mercados. Estas iniciativas premian la "pro-actividad" mediante la concesión de permisos y habilitaciones por parte de la municipalidad para el desarrollo de diversas actividades en la calle, favoreciendo el ímpetu privado y al mismo tiempo apelando a un fuerte contenido cultural que moviliza emociones y sensaciones ligadas a lo cool. Un claro ejemplo es el Festival Food Trucks: 
La estética de cada uno de los carros marcaba distinciones. Se pudo apreciar desde un ex colectivo de línea convertido en una pizzería ambulante, pasando por utilitarios de Volkswagen de la década del '70 pintados de colores, hasta uno nuevo dedicado a la venta de hamburguesas que rinde homenaje a Los Ramones ("Un festival como prueba", 2016).

En virtud de estas caracterizaciones que juegan entre lo vintage y lo vanguardista, lo cosmopolita y lo local, lo viejo y lo joven, aparece lo que algunos autores han llamado "pastiche en la cultura" (Anderson, 2000), como un signo ineludible de la lógica posmoderna. El pastiche en la cultura consiste en la imitación de estilos del pasado que lo intentan renovar. Se trata de una "máscara muerta presente y visible en una arquitectura y un diseño donde todo está acomodado en su lugar y se sostiene como escenografía más que como un espacio donde transcurrir la vida y sus avatares" (Murillo, 2012, p. 169). Con el artilugio del pastiche se imita algo del pasado, se lo resignifica para volverlo un aspecto estético, vaciándolo de aquellas dimensiones que pueden ser retomadas para criticar severamente el presente a partir de lo que fue. Tal como dice Perry Anderson, "la posmodernidad deja de ser una mera ruptura estética o un cambio epistemológico para convertirse en señal cultural de un nuevo estadio de la historia del modo de producción dominante" (Anderson, 2000, p. 77).

\section{La construcción de escenas urbanas: urbanismo escenográfico, urbanismo a la carta}

En sintonía con el pastiche cultural, lo cool en su dimensión urbana se construye al modo de una escena. El montaje de escenas urbanas, sostienen Girola et al:

Se plasma generalmente apelando a la cultura y sus derivados (el patrimonio, el pasado/ memoria, la diversidad cultural, el espectáculo, el arte, etc.) como estrategias predilectas de intervención que permiten la conformación de lugares únicos y pintorescos, a la vez que se constituyen como auténticas áreas de oportunidad para la realización de fabulosos negocios (Girola et al., 2011).

El urbanismo escenográfico, y con él los imperativos culturales del diseño, la modernización, la belleza y la distinción, asumen cada vez mayor importancia en la promoción y construcción de las ciudades. De este modo, la cultura y los elementos que le otorgan a lo urbano cierto sello, marca, 
singularidad, se transforman en recursos que devienen mercancías a ser vendidas ${ }^{20}$.

Las iniciativas estudiadas se inscriben en esa tendencia. La Calle Recreativa, el programa Mi bici-Tu bici, las iniciativas gastronómicas Street Food y Food Trucks apuntan a crear sitios de entretenimiento, recreación y encuentro entre sujetos en espacios bellos, limpios y con estilo. Los lugares en los que se emplazan son diseñados con criterios estéticos que buscan generar ciertas marcas culturales, entre las que se destacan las marcas de gestión (el color naranja de las bicicletas del programa Mi bici-Tu bici asociado al partido gobernante) y las marcas de clase (el vintage de la alta moda y el apelativo gourmet de las comidas que se ofrecen en el Food Truck y en la Street Food).

Otro de los rasgos que atraviesa a las iniciativas es su despliegue en la calle, en el espacio público o de acceso público. La calle, como medio de circulación -tal como aparece en el programa Mi bici-Tu bici-, como medio de ocio y deporte -tal como están diseñados el Paseo de los Olímpicos y la Calle Recreativa- o como medio de consumo -modalidad en que se desarrolla el Street Food y el Food
Truck-, cumple dos funciones estratégicas. Por un lado, permite proyectar la idea de acceso libre a estos espacios, que son público-participativos, de encuentro y mixtura global, y, por el otro, funciona como vidriera de la ciudad.

Como todo espacio público, la calle y las intervenciones que se despliegan en ella son pensadas como espacios que habilitan el encuentro de sujetos heterogéneos bajo la premisa que estas contribuyen a la gestión democrática de las ciudades, a la solidaridad y la participación ciudadana. La Calle Recreativa así es entendida por la Municipalidad de Rosario, que afirma en su página web ("Calle Recreativa", s.f.) que la recuperación de las calles para el encuentro ciudadano y la promoción de la convivencia ciudadana con valores democráticos, respeto y tolerancia son beneficios derivados de la existencia de este programa. Mi bici-Tu bici también incorpora la dimensión recreativa y de encuentro. Al respecto, son ilustrativas las palabras de la actual intendenta Mónica Fein, para quien el programa "debe estar conectado para que la gente pueda ir a trabajar, a estudiar, a encontrarse, a divertirse a través de la bici pública" ("A la espera", 2016).

20 Algunas de estas iniciativas producen degradación medioambiental o destrucción del patrimonio histórico de la ciudad. Un ejemplo es la quita del adoquinado en las calles aduciendo modernización, pero esto "impide el filtrado cuando llueve, no colaborando con la absorción. Una calle asfaltada resulta más conveniente para la circulación, pero tiene impacto ambiental y socio-histórico" (Sanjurjo y Sanjurjo, 2013, p. 213). 
A pesar de la dimensión pública y de encuentro con que son enunciadas las iniciativas analizadas, no todos/as los/as ciudadanos/as son contemplados en ellas, ya que el efectivo acceso y goce de estos espacios y objetos se circunscribe, en el caso del programa Mi bici-Tu bici, por un lado al pago de un monto, a la tenencia de un servicio o demostrando poseer empleo registrado legalmente y, por otro lado: a la circulación y habitación en un sector urbano específico: el área central. Por lo tanto, el centro y sus residentes y visitantes son los/as destinatarios/as predilectos/as a los que van dirigidas estas iniciativas. Esto también se constata al rastrear las fotografías y los videos que se utilizan para retratar, difundir y publicitar, en diversos medios y redes sociales, las políticas e iniciativas analizadas en este artículo. En ellos se visualiza la puesta en funcionamiento de lo que Sacchi (2010) denomina -retomando a Deleuze y Guattari- "máquina de rostridad", ya que los/as sujetos que las utilizan, que participan de las múltiples iniciativas, se destacan por sus rasgos blancos, por ser jóvenes, activos/as, predispuestos/as, sonrientes y saludables. Esos son los rostros que habitan esos espacios y que se muestran como representación de la ciudad.

Por otro lado, la calle y las políticas que la tienen como espacio de concreción aparecen como vidriera, en cuanto tienen gran visibilidad mediática que, a bajo costo, las asocia a países del llamado "primer mundo", imprimiéndole un sentido cosmopolita. Según Delgadillo (2014), políticas como las bici-sendas, los planes estratégicos y las actuaciones de marketing urbano constituyen un conjunto de acciones urbanas, un "menú" de "recetas probadas" en distintos contextos para confrontar "con éxito" algunos problemas y desafíos. Este "menú" emula modas urbanísticas europeas y anglosajonas que continúan siendo una referencia en nuestra América.

Como reverso de estas iniciativas urbanas, a nivel subjetivo se configura lo que se ha denominado "turistificación de la vida cotidiana" (Vera et al., 2016, p. 202), vale decir, en el marco de la expansiva mercantilización urbana que gradual e incesantemente se desarrolla anidan y crecen las expectativas por conformarse en atracción turística. Explican los/as autores/as que en la medida en que se intensifica la actividad urbana ligada a los servicios, aumentan las posibilidades de concebir a una ciudad, sin tradición turística, en un polo receptivo de turistas nacionales y/o internacionales. "Así, estrategias comunicacionales sumadas a herramientas de gestión política han conducido un proceso de turistificación de la ciudad incrementando escenografías, itinerarios y sentidos urbanos" (Vera et al., 2016, p. 202).

Tal como plantean Sanjurjo y Sanjurjo, "no hay nada malo en el turismo como actividad, pero el problema radica en la dinámica de acceso al arte y la cultura que una política de Estado plantea" 
(2013, p. 213). El inconveniente radica en que se fomente, entonces, una política de Estado que priorice el acceso a lo urbano y su cultura vía prácticas turísticas elitistas, globalizantes, que encuentran en el "dócil ciudadano turista", o en el ciudadano consumidor, el sujeto al cual dirigirse acorde a ese modelo, en contraposición a un sujeto político o a un sujeto de derechos.

\section{Reflexiones finales}

A lo largo del trabajo nos propusimos problematizar un conjunto de iniciativas urbanas en Rosario: Street Food - Feria gastronómica callejera, el Festival Food Trucks, la Calle Recreativa, el Paseo de los Olímpicos y el programa Mi bici-Tu bici. Teniéndolas como disparadores, interesaba indagar, aun de un modo exploratorio, la manera en que los gobiernos locales gestionan diversas iniciativas gubernamentales y las implementan; qué rumbo han tomado éstas en los últimos años; cómo se construye ciudad y para quién; cuánto contribuyen estas iniciativas a tornar más igualitaria o no la ciudad; de qué modo son movilizados los deseos y afectos de los sujetos y cuáles son las subjetividades que inducen esas actuaciones.

Para desandar algunos de esos interrogantes, la perspectiva conceptual que informó el trabajo orientó el análisis hacia tres dimensiones mutuamente implicadas: las condiciones que hicieron posible las iniciativas, la racionalidad política que las constituyó y las tecnologías de gobierno que desplegaron. Con respecto a la primera dimensión, la ciudad de Rosario, a lo largo de las últimas décadas, desarrolló una tradición de iniciativas atravesadas por una racionalidad política empresarial de gestión. Racionalidad que exhortó al gobierno local a asumir un rol activo en lo económico, facilitador de la actividad privada y de la competitividad de la ciudad en el mercado global. El Plan Estratégico Rosario (1998), la creación y rehabilitación de infraestructuras creativas y la urbanización del frente costero fueron algunas de las expresiones de esta nueva modalidad de planificar las políticas e iniciativas urbanas. Modalidad que, a un ritmo vertiginoso, fue dando mayor capacidad de incidencia al empresariado local en la planificación de la ciudad.

Con respecto a la segunda dimensión de análisis, encontramos que la racionalidad empresarial de gestión urbana adoptó una estrategia centrada en mostrar a Rosario en una vidriera nacional e internacional como una ciudad cosmopolita, joven, cultural y turística, una ciudad cool. La racionalidad de lo cool implicó que Rosario se convirtiese en una marca, adoptase un color propio y que las iniciativas en ella desplegadas desarrollaran una estética y un estilo capaces de movilizar emociones 
y sensaciones asociadas a una cultura estilizada, bella, sustentable, saludable y cosmopolita. Los/ as destinatarios/as predilectos de estas iniciativas fueron los/as jóvenes de clases medias y/o altas residentes en los barrios céntricos de la ciudad que aspiran a recorrer circuitos privilegiados de entretenimiento y distracción, acordes a los que se ofrecen en las principales ciudades del mundo.

Mediante una profunda articulación con el ámbito empresarial local e internacional, las iniciativas analizadas activaron tecnologías de gobierno consistentes en visualizar espacios y escenas urbanas que, apelando a los imperativos culturales del diseño, la belleza, la distinción y lo saludable, conformaron lugares pintorescos y recreativos predispuestos para su consumo. En este marco, la calle, como espacio de despliegue de las distintas iniciativas, cumplió dos funciones estratégicas permitiendo proyectar la idea de acceso libre a estos espacios y funcionar como vidriera de la ciudad.

A pesar de que la dimensión pública y de encuentro es remarcada en la enunciación de las iniciativas analizadas, no todos/as los/as ciudadanos/as fueron contemplados/as en ellas, ya que el efectivo acceso y goce de estos espacios y objetos se circunscribió a la posibilidad de consumo y al acceso a la centralidad urbana. Por lo tanto, el centro de la ciudad, sus residentes y visitantes fueron los/ as destinatarios/as predilectos/as, destinatarios/as a la vez constituidos como sujetos blancos, activos/as, predispuestos/as, sonrientes, saludables y deseantes. Sujetos convertidos en ciudadanos turistas o consumidores, en contraposición a sujetos políticos o a sujetos de derechos.

Frente a la implementación de estas iniciativas público-privadas que hemos denominado del orden del pastiche cultural, de lo cool y del urbanismo escenográfico, cabe introducir unas preguntas finales a modo de interrogantes futuros: ¿cuáles son los efectos de las acciones que no consideran al espacio urbano ni a la ciudad como algo que debe modelarse en función de objetivos y proyectos sociales, sino de acuerdo con objetivos y principios del orden de lo estéticamente bello, a-histórico e individualizado?; ¿cómo y a través de qué estrategias es posible problematizar estas potencialidades que son juzgadas en general y legitimadas, como atractivas y necesarias para construir una "ciudad pujante"?; ¿cómo construir, habitar, transitar y asir una ciudad más igualitaria, menos estriada, menos fragmentada, más sincera, más justa y menos escenografiada? Como sugieren Henri Lefebvre (1973) y David Harvey (2013), cuestionar el tipo de ciudad que se quiere construir es una acción políticamente inseparable de la reflexión acerca de qué tipo de sujetos se desea ser. 


\section{Referencias bibliográficas}

A la espera de la primavera, la feria "Street Food Rosario" se apoderó de Oroño (2016, 18 de septiembre). Conclusión. Recuperado de http://www. conclusion.com.ar/2016/09/a-la-espera-de-la-primavera-la-feria-street-food-rosario-se-apoderode-orono/.

Améndola, G. (2000). La ciudad posmoderna. Magia y miedo de la metrópolis contemporánea. Madrid, España: Celeste Ediciones.

Anderson, P. (2000). Los orígenes de la posmodernidad. Barcelona, España: Anagrama.

Arantes, 0., Vainer, C., y Maricato, E. (2000). A cidade do pensamento único. Desmanchando consensos. Petrópolis: Vozes.

Barry, A., Osborne, T., y Rose, N. (1996). Foucault and political reason. Liberalism, neo-liberalism and rationalities of government. Londres, Inglaterra: UCL.

Brizuela, F. (2015). La configuración de Rosario en clave empresarial. Transformaciones urbanas durante las gestiones socialistas. Revista Cátedra Paralela, (12), 283-306.

Burchel, G., Gordon, C., y Miller, P. (Eds.) (1991). The Foucault effect. Studies in governmentality. USA: The University of Chicago Press.

Calle Recreativa (s.f.). Municipalidad de Rosario. Recuperado de http://www.rosario.gov.ar/web/ciudad/ deportes-y-recreacion/calle-recreativa.
La Calle Recreativa cumple tres años y se afianza como un clásico de Rosario (2013, 3 de noviembre). La Capital. Recuperado de http://www.lacapital. com.ar/la-ciudad/la-calle-recreativa-cumpletres-anos-y-se-afianza-como-un-clasico-rosario-n427360.html.

Campana, M. (2012). Medicalizar la asistencia, asistencializar la salud. Rosario, Argentina: Prohistoria Ediciones.

Ciudades competitivas: Un nuevo paradigma empresarial en desarrollo espacial (2007). OCDE. Recuperado de https://www.oecd.org/cfe/regionalpolicy/38747586.pdf.

Conta, M. (2015, 31 de octubre). Street Food Rosario: una propuesta cultural y gourmet sobre Boulevard Oroño. Porven. Recuperado de http://porven.com. ar/street-food-rosario-una-propuesta-cultural-ygourmet-sobre-boulevard-orono/16647.

Cuenya, B. (2000). Globalización y políticas urbanas. Transformaciones de las políticas urbanas en la ciudad de Buenos Aires. Revista Sociológica, 15(42), 37-57

X Congreso de la Red de Ciclovías Recreativas de las Américas (s.f.) Municipalidad de Rosario. Recuperado de http://www.rosario.gov.ar/web/ciudad/ deportes-y-recreacion/congreso-de-la-red-deciclovias-recreativas-de-las-americas/x-congreso.

Delgadillo, V. (2014). Urbanismo a la carta: teorías, políticas, programas y otras recetas urbanas para ciudades latinoamericanas. Cadernos Metrópole, 16(31), 89-111. https://doi. org/10.1590/2236-9996.2014-3104. 
Un festival como prueba piloto de los food trucks en Rosario (2016, 22 de abril). La Capital. Recuperado de http://www.lacapital.com.ar/la-ciudad/ un-festival-como-prueba-piloto-los-food-trucksrosario-n782352.html.

Foucault, M. (2007). Nacimiento de la biopolítica. Buenos Aires: Fondo de Cultura Económica.

(2006). Seguridad, territorio y población. Buenos Aires: Fondo de Cultura Económica.

(2001). El sujeto y el poder. En Dreyfus, H. y Rabinow, P. Michel Foucault. Más allá del estructuralismo y la hermenéutica (pp. 241-260). Buenos Aires, Argentina: Nueva Visión.

García Delgado, D. (1998). Nuevos escenarios locales. El cambio en el modelo de gestión. En Venesia, J.C. (Comp.). Políticas públicas y desarrollo local. Rosario, Argentina: Instituto de Desarrollo Regional.

Giavedoni, J. (2012). Gobernando la pobreza: la energía eléctrica como dispositivo de gestión de los sectores populares. Rosario, Argentina: Homo Sapiens.

Girola, M. F., Yacovino, M. P., y Laborde, S. (2011). Recentrando la centralidad: Proceso de recualificación urbana y espacio público en la ciudad de Buenos Aires desde una perspectiva etnográfica. Cuaderno Urbano, 10(10), 25-40.

Grinberg, M. (2007). Gubernamentalidad: estudios y perspectivas. Revista Argentina de Sociología, 5(8), 95-110.

Harvey, D. (2013). Ciudades rebeldes. Del derecho a la ciudad a la revolución urbana. España: Akal. Akal.

(2007). El nuevo imperialismo. Madrid, España:

Klein, N. (2012). No logo. El poder de las marcas. Buenos Aires, Argentina: Paidós.

Laval, C., y Dardot, P. (2013). La nueva razón del mundo. Ensayo sobre la sociedad neoliberal. Barcelona, España: Gedisa.

Lefrebvre, H. (1973). El derecho a la ciudad. España: Península.

Los reconocimientos de "Rosario, Empresa de Todos" (2010, 12 de noviembre). ON24. Recuperado de http://www.on24.com.ar/archivo/40827.

Marinis, P.d. (1999). Gobierno, gubernamentalidad, Foucault y los anglofoucaultianos (o un ensayo sobre la racionalidad política neoliberal). En F.G. Selgas y R.R. Torre (Eds.). Globalización, riesgo, reflexividad. Tres temas de la teoría social contemporánea (pp. 73-103). Madrid, España: Centro de Investigaciones Sociológicas.

Mendizábal, N. (2006). Los componentes del diseño flexible en la investigación cualitativa. En: Vasilachis De Gialdino, I. (Coord.), Estrategias de investigación cualitativa (pp. 65-103). Buenos Aires, Argentina: Gedisa.

Mongin, 0. (2006). La condición urbana. La ciudad a la hora de la mundialización. Buenos Aires, Argentina: Paidós.

Murillo, S. (2016). Problematizar la centralidad de "el sentido" en la sociedad neoliberal. Documento presentado en Conferencia Programa de Estudios sobre Gubernamentalidad y Estado (PEGUES), Rosario. 
Murillo, S. (2012). Posmodernidad y neoliberalismo. Reflexiones críticas desde los proyectos emancipatorios de América Latina. Buenos Aires, Argentina: Ediciones Luxemburgo.

Murillo, S. (2008). Producción de pobreza y construcción de subjetividad. En Cimadamore, A. D. y Cattani A. D. (Comps.) Producción de pobreza y desigualdad en América Latina. Bogotá, Colombia: Siglo del Hombre.

Nicoli, M. y Paltrinieri, L. (2014). Il management di sé e deglialtri. Autaut, (362), 49-74.

Paseo de los Olímpicos (s.f.). Municipalidad de Rosario. Recuperado de https://www.rosario. gov.ar/web/ciudad/deportes-y-recreacion/ paseo-de-los-olimpicos.

Un paseo olímpico por avenida Pellegrini (2015, 31 de marzo). Rosario3.com. Recuperado de https:// www.rosario3.com/noticias/Un-paseo-olimpicopor-avenida-Pellegrini-20150331-0036.html.

Plan Estratégico Rosario (1998). Municipalidad de Rosario. Recuperado de http://www.rosario.gov.ar/ sitio/verArchivo?id=4718\&tipo=objetoMultimed ia.

Rose, N., y Miller, P. (1992). Political power beyonce the State: Problematics of government. The British Journal of Sociology, 43(2), 173 -205. https://doi. org/10.2307/591464.

Sacchi, E. (2010). Rosario: La experiencia política de la ciudad-empresa. Cuaderno Urbano, 9(9), 77-90.
Sánchez, L. y Ginga, L. (2014). Urbanización y relocalización territorial en el marco de "ciudades más seguras". Una aproximación al estudio de las experiencias desarrolladas en las ciudades de Rosario y Córdoba. Argumentos. Revista de crítica social, (16), 167-198.

Sanjurjo, L., y Sanjurjo, E. (2013). Políticas de olvido: la gestión neoliberal de los patrimonios históricos y culturales. En Marín, J. (Comp.). La ciudad empresa. Espacios, ciudadanos y derechos bajo la lógica de mercado (pp. 213-222). Buenos Aires, Argentina: Centro Cultural de la Cooperación Floreal Gorini.

Socoloff, I. (2013). Polos, distritos y enclaves en Buenos Aires. De la pedagogía del inversor a la "inflación" de los precios del suelo. En Marín, J. (Comp.). La ciudad empresa. Espacios, ciudadanos y derechos bajo la lógica de mercado (pp. 67-88). Buenos Aires, Argentina: Centro Cultural de la Cooperación Floreal Gorini.

Street Food Rosario: llega la segunda edición de la feria gastronómica callejera $(2015,25$ de septiembre). Impulso. Recuperado de http://www.impulsonegocios.com/contenidos/2015/09/25/Editorial_37537.php.

Theodore, N., Peck, J., y Brenner, N. (2009). Urbanismo neoliberal: la ciudad y el imperio de los mercados. Temas Sociales, 66, 1-11.

Vera, P., Roldán, D., y Pascual, C. (2016). La construcción escenográfica de la ciudad. Espacio público, turismo e itinerarios en Rosario (Argentina). Chasqui Revista Latinoamericana de Comunicación, (130), 199-219. 